\title{
Tribological analysis of the surface layer coated by sintered serpentine-reinforced composites
}

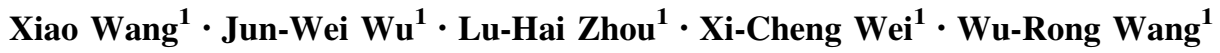

Received: 26 August 2017/Revised: 8 October 2017/Published online: 2 November 2017

(C) The Chinese Society for Metals and Springer-Verlag GmbH Germany 2017

\begin{abstract}
In this work, the serpentine powders were sintered to make the serpentine-reinforced Al-matrix composites, and the microstructures of which were characterized by differential scanning calorimetry, thermal gravimetric analyzer, and $\mathrm{X}$-ray diffractometer. Scanning electron microscopy equipped with energy dispersive spectroscopy. Results show that the sintered serpentine powders were deeply absorbed on the worn surface and embedded in the furrows and scratches of the matrix, forming a self-repairing surface layer which reduces the friction coefficient. The surface layer coated by serpentine was compact, dense, and uniform with the friction time prolonged, compensating the worn loss and increasing the matrix mass.
\end{abstract}

KEY WORDS: Serpentine; Friction; Wear; Surface layer

\section{Introduction}

With increasing demand for low wear and less maintenance of mechanical components, many potential approaches have been proposed. Owing to the excellent tribological properties, low cost, simple preparation process, and environmental friendship characteristics [1-4], the serpentine has been widely investigated. Serpentine is a kind of hydrous phyllosilicate mineral in nature, which is stoichiometrically represented by the chemical formula of $\mathrm{Mg}_{2} \mathrm{Si}_{2} \mathrm{O}_{5}(\mathrm{OH})_{4}$. For tribological applications, the serpentine powder as an additive in oil has been widely investigated. A self-repairing protective layer can be formed on worn ferrous surface [5], decreasing the friction coefficient

Available online at http://link.springer.com/journal/40195

Xi-Cheng Wei

wxc1028@staff.shu.edu.cn

1 School of Materials Science and Engineering, Shanghai University, Shanghai 200072, China and preventing substrate from being damaged [6, 7]. Physical model [8] and phenomenological model [9] were developed to discuss the formation mechanism of the surface-coated layer. Physical and mechanical effects, such as adhering and spreading on the worn surface, were believed to lead to the formation of the auto-reconditioning protective layer [10]. In addition, mechanochemical and thermochemical reactions were also believed to occur [11].

However, the essence and physical nature of the formation of the self-repairing surface layer have not been sufficiently clarified [12]. For example, Jia et al. [13] presented a PTFE (Polytetrafluoroethylene)/serpentine composite and found the hybrid transfer film generated on the surface of mating pair, which was likely responsible for the lower wear rate. Yang et al. [14]. have fabricated a nano serpentine-potassium acetate intercalation compound and found that the addition of the serpentine in the fabric self-lubricating liner improved the wear resistance. Their work mainly conjectured the formation mechanisms with the untreated serpentine doped in the lubricant. Obviously, more efforts are required to further explore the mechanisms 
of the function of the serpentine as filler in improving tribological behavior.

Yu et al. [15] have found that the thermal activations on the serpentine at a temperature ranging from 300 to $600{ }^{\circ} \mathrm{C}$ increased the film forming ability and tribofilm completeness, and accordingly further improved the tribological properties. In this work, the serpentine-reinforced Al-matrix composites were fabricated using the powder metallurgy technique. The sintering process can be seemed as the thermal activation on serpentine. The composite was then used as a model to explore the function of serpentine in ameliorating the friction and wear.

\section{Experimental procedure}

\subsection{Materials}

The serpentine powders were purchased from Baosteel, China. Figure 1 shows scanning electron microscopy (SEM) image of the serpentine powders with the average size of $0.1-1 \mu \mathrm{m}$ [16]. The aluminum powders (average particle size: $75 \mu \mathrm{m}, 99.0 \% \mathrm{Al}$ ) and silicon powders (average particle size: $48 \mu \mathrm{m}, 99.0 \% \mathrm{Si}$ ) were used as the starting materials. The composite fabrication process is schematically shown in Fig. 2. In addition, the fabrication parameters of the composite are concluded in Table 1.

In detail, $\mathrm{Al}, \mathrm{Si}$, and sintered serpentine powders were mixed (the mass ratio of $85.36: 11.64: 3$ ) [16] in a high energy planetary ball mill at $560{ }^{\circ} \mathrm{C}$ for $3 \mathrm{~h}$, with the weight ratio of ball to powder of 10:1 and the milling speed of $300 \mathrm{rpm}[17,18]$. Then, the powder mixtures were coldpressed uniaxially into cylindrical performs at the pressure of $350 \mathrm{MPa}$ [19].

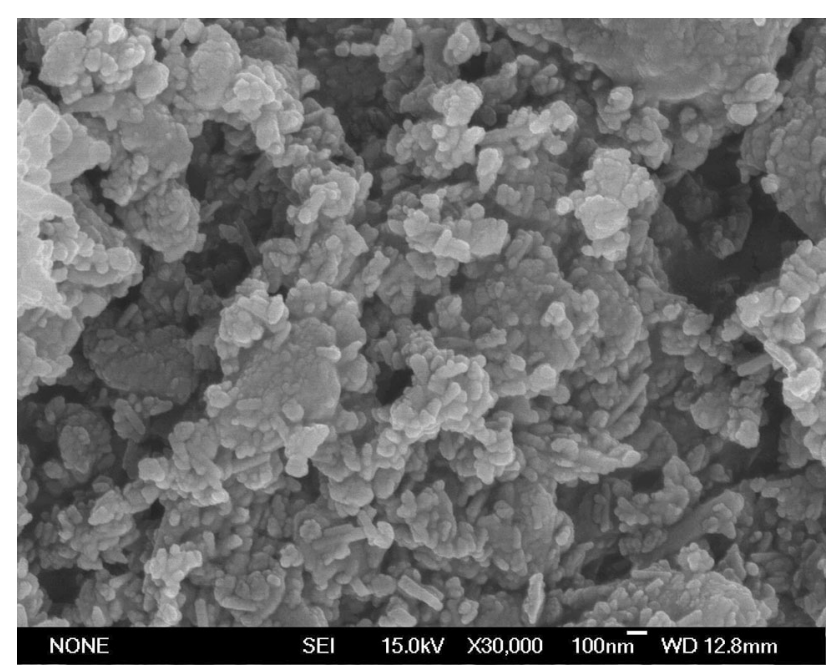

Fig. 1 SEM image of the serpentine powder
Sintering was performed using a YFK-60X400 pipe electric furnace. The compacts were sintered at the temperature of $560{ }^{\circ} \mathrm{C}$ for $3 \mathrm{~h}$ in the protective atmosphere with $99.9 \%$ purity nitrogen, followed by furnace cooling.

\subsection{Wear test}

Sliding friction test was carried out on an MM-W1 (China Jinan Assay Group instrument) three pin-on-disk apparatus in a laboratory environment using a normal load of $70 \mathrm{~N}$, a sliding speed of $0.23 \mathrm{~m} / \mathrm{s}$, and test duration of $2 \mathrm{~h}$ [16].

The friction pair was lubricated by Shell HELIX HX5 lubricating oil to eliminate the influence of air. The disk was rotated, and the pin was fixed during the test. The schematic diagrams and dimensions of the pin and disk are shown in Fig. 3.

The pin was a composite fabricated in this study. The friction coefficient between three pins and a disk was recorded by an attached computer sensor. The three pins were cut by machining into cylindrical which could ensure the coaxial degree and the parallelism of upper and lower working sides. Furthermore, illumination method was used to determine whether the three pins and the disk contacted completely, and if not, gaskets would be added. Therefore, the parallelism was well ensured which could lead to the applied load being distributed equally on the three pins. To ensure the reproducibility, at least three sliding friction tests were carried out for each material under the same test conditions.

The disk was made of quenched and tempered AISI 1045 steel with the hardness of about 40 HRC. The surface roughness of the disk and pin specimens was $\mathrm{Ra}$ $0.05-0.1 \mu \mathrm{m}$. Before and after test, the specimens were cleaned with petroleum ether and absolute ethyl alcohol for 15 min by ultrasonic cleaner.

\subsection{Characterization method}

The optic metallography (OM) for samples was prepared by standard metallurgical methods, i.e., grinding on $\mathrm{SiC}$ abrasive papers and polishing with $1 \mu \mathrm{m}$ diamond paste, followed by etching with Keller's reagent (an aqueous solution containing $1 \mathrm{vol} \% \mathrm{HF}, 1.5 \mathrm{vol} \% \mathrm{HCl}$, and $\left.2.5 \mathrm{vol} \% \mathrm{HNO}_{3}\right)$. The disk specimens were firstly plated with nickel to protect the worn surface, and then, they were cut by linear cutting machine through the center which was perpendicular to the sliding direction in order to observe the surface layer.

The morphologies of the mixed powders, the composite microstructure, the worn surface, and cross section of the samples were observed using a HITACHI SU-1500 SEM equipped with an Oxford energy dispersive spectroscopy (EDS). 


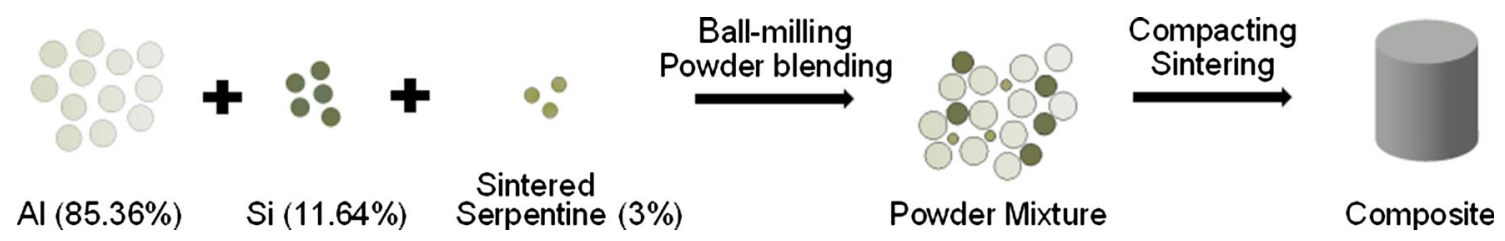

Fig. 2 Schematic diagram of the composite fabrication process

Table 1 Fabrication process of the composite

\begin{tabular}{ll}
\hline Parameter & Values \\
\hline Ball milling time & $3 \mathrm{~h}$ \\
The weight ratio of ball to powder & $10: 1$ \\
The milling speed & $300 \mathrm{rpm}$ \\
Compacting pressure & $350 \mathrm{MPa}$ \\
Sintering temperature & $560{ }^{\circ} \mathrm{C}$ \\
Sintering time & $3 \mathrm{~h}$ \\
Protective atmosphere & $99.9 \%$ purity nitrogen
\end{tabular}

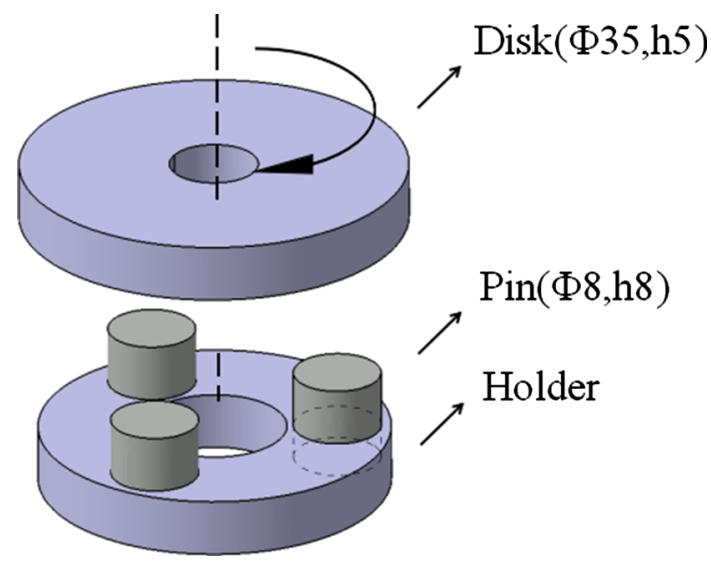

Fig. 3 Schematic diagrams and dimensions of pin and disk

The phase analysis was carried out by an $18 \mathrm{KW} \mathrm{D/}$ MAX2500 V X-ray diffractometer (XRD) using $\mathrm{Cu} K_{\alpha}$ radiation at a scan step of $2 \% \mathrm{~min}$. The decomposition temperature of serpentine powders was investigated by an STA449F3 thermal analyzer which allows simultaneous differential scanning calorimetry (DSC) and thermogravimetry (TG) analysis. The range of scanning temperature was chosen from room temperature to $1000{ }^{\circ} \mathrm{C}$, while the heating rate was at $10^{\circ} \mathrm{C} / \mathrm{min}$. The protection gas was nitrogen.

\section{Results}

Figure 4 is the XRD patterns of original and sintered serpentines at $560{ }^{\circ} \mathrm{C}$. The diffraction peaks can be indexed to those of antigorite with $d=0.3617$ and $0.2769 \mathrm{~nm}$. After

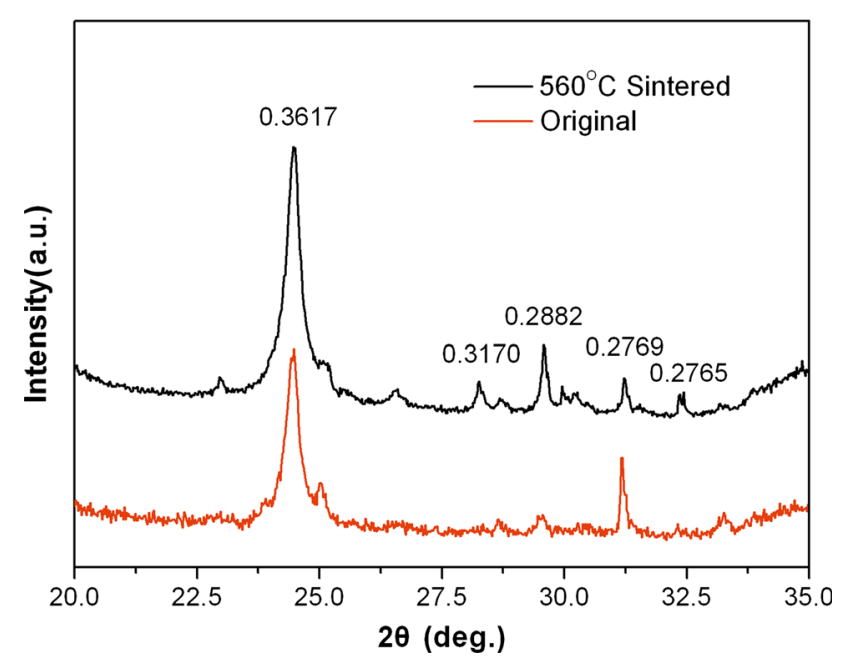

Fig. 4 XRD patterns of original and $560{ }^{\circ} \mathrm{C}$ sintered serpentine

being sintered at $560{ }^{\circ} \mathrm{C}$, three weak diffraction peaks of $d=0.3170,0.2882$, and 0.2765 appeared, showing that forsterite appeared. It means that hydroxyl in octahedral sheet began to dehydrating with the layered structure of serpentine still maintained.

The DSC and TG curves of the serpentine powder are shown in Fig. 5. After being sintered at $560{ }^{\circ} \mathrm{C}$, a wide exothermic peak appeared in the DSC curve, and the corresponding TG curve declined dramatically. It was caused by dehydrating absorbed water from the serpentine powder. The mass percent of adsorbed water accounted for $12 \%$ of serpentine weight. As a large amount of bonds like $\mathrm{Si}-\mathrm{O}$

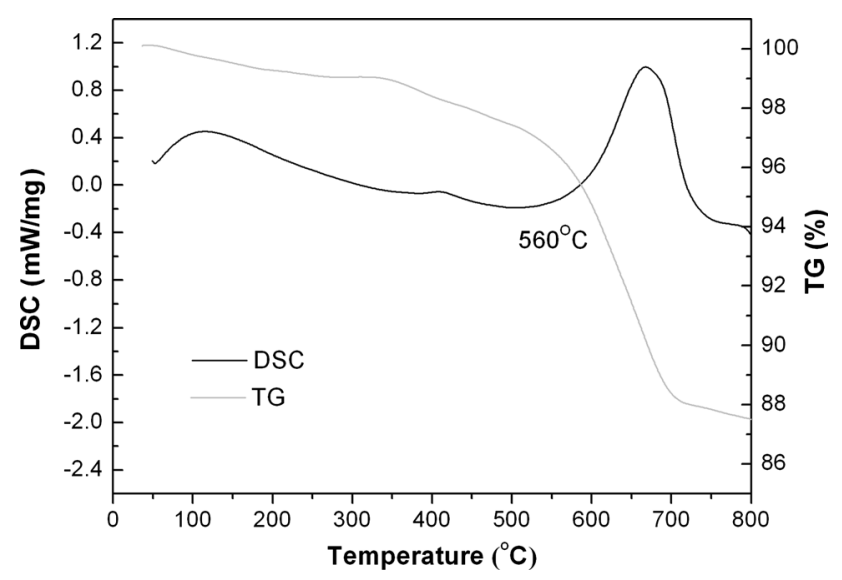

Fig. 5 DSC and TG curves of the serpentine powder 
and $\mathrm{Si}-\mathrm{O}-\mathrm{Si}$ existed on the sheets of serpentine, it can be indicated that dehydration and dehydroxylation reaction endowed serpentine powders with better capability of oxygen release.

It has been reported that the specific surface area of the original serpentine particles can be increased by more than 20 times after being heated at $550{ }^{\circ} \mathrm{C}$ [20]. After sintering at $560{ }^{\circ} \mathrm{C}$, the adsorptive capacity of serpentine could be improved. Serpentine-reinforced Al-matrix composites can thus be fabricated.

Figures 6 and 7 present the SEM morphologies of the powder and the composite microstructure, respectively. As can be seen from Fig. 6, the ball-milled powders were mainly composed of large $\mathrm{Al}$ particles, and $\mathrm{Si}$ and serpentine particles which were absorbed on the Al particles. In addition, some agglomerated $\mathrm{Si}$ and serpentine particles can also be found. After being cold-pressed and sintered, the microstructure of the composite was shown in Fig. 7.

Figure 8 illustrates the element distributions of Fig. 7. In Fig. 8, the white dots present $\mathrm{Al}$ element, the green dots present $\mathrm{Mg}$ element, the red dots present $\mathrm{O}$ element and the blue dots present $\mathrm{Si}$ element. It proves that the black matrix in Fig. 7 was Al, which was formed by the large Al particles of the ball-milled powders. Furthermore, the reticular white color substance was $\mathrm{Si}$ and serpentine. It is obvious that $\mathrm{Mg}$ and $\mathrm{O}$ elements came from the serpentine powder, and their content was fairly high in the boundaries of the $\mathrm{Al}$ particles. These serpentine powders would play a key role in improving the tribological properties.

Figure 9 presents the variation of friction coefficient as a function of sliding time. The friction coefficient of the traditional Al-Si composite increased steadily with the time prolonged, reaching its peak at 0.066 . By contrast, the friction coefficient of the composite containing serpentine powder was much lower. At the first $3600 \mathrm{~s}$, the friction

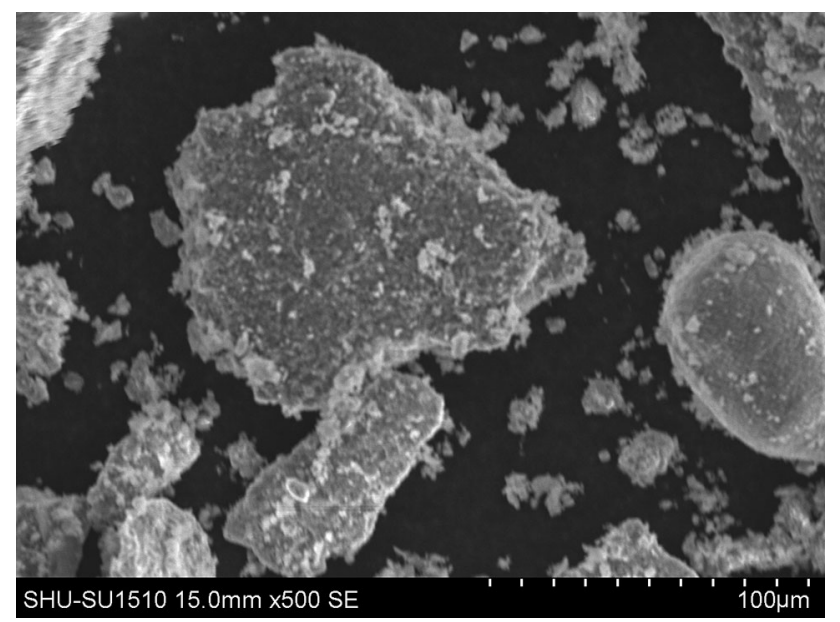

Fig. 6 SEM morphology of ball-milled powders

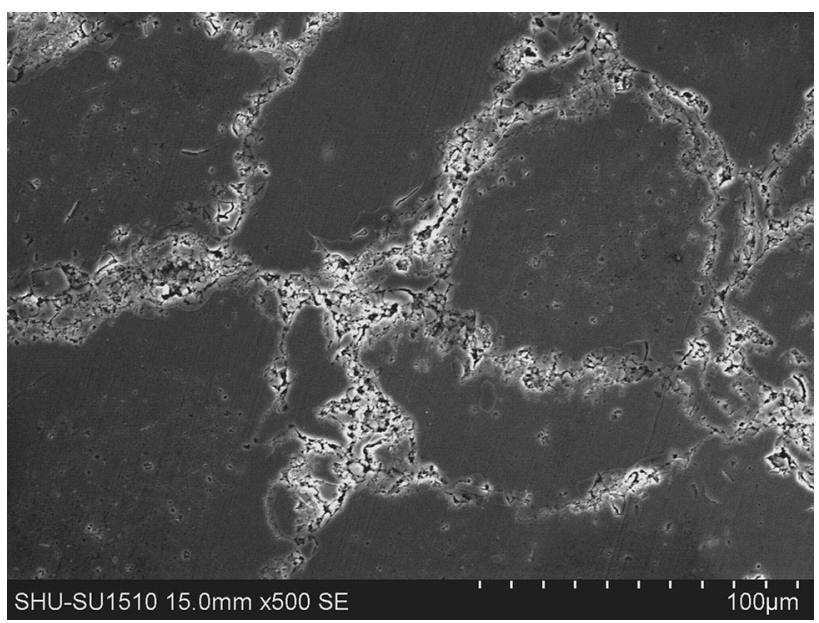

Fig. 7 SEM morphology of the composite microstructure

coefficient kept stable at about 0.041 . After the time point of $5400 \mathrm{~s}$, it gradually remained at about 0.038 .

Figure 10 shows the mass increment of disk as a function of test time. The formation of the surface layer can increase the mass of the sample. Qi et al. [21] also found negative mass loss in specimens using serpentine additive in their lubricating oil. Similarly, the mass increment phenomenon was also presented in Fig. 10. Megahed et al. [22] and Ashrafi et al. [23] reported that the reinforcements in Al-matrix had a good effect on anti-wear property. In addition to the reinforcement effect, some other specific reasons can be analyzed from the SEM observation of the worn surface.

Figure 11a, $\mathrm{b}$ is SEM morphologies of the worn surface of the disk after 1800 and 5400 s sliding time, respectively. Figure 12 shows the corresponding cross-section morphologies of Fig. 11. From Fig. 11a, it can be seen that after $1800 \mathrm{~s}$ sliding time, the worn surface of the disk had obvious furrows, which were the typical abrasive wear morphology. The furrows and grooves in sliding direction, formed by the wear debris like serpentine and steel particles, were wide and deep. EDS spectra in Fig. 13a show that under the effect of compressive stress and friction stress, the active serpentine particle was deeply absorbed on the worn surface and embedded in the furrows and scratches of the matrix, as can be seen in Figs. 11a and 12a.

With the friction time prolonged, the furrows and grooves disappeared, and the worn surface was completely covered by a surface layer which was different from the steel matrix. As can be seen from Fig. 12, the surface layer became compact, dense, and uniform during friction process. More area of the surface layer covered (Fig. 11), more mass of the specimen would get. As the surface layer was formed, the mass rising rate of the surface layer could compensate or even exceed the mass loss rate caused by the friction and wear (Fig. 10). 

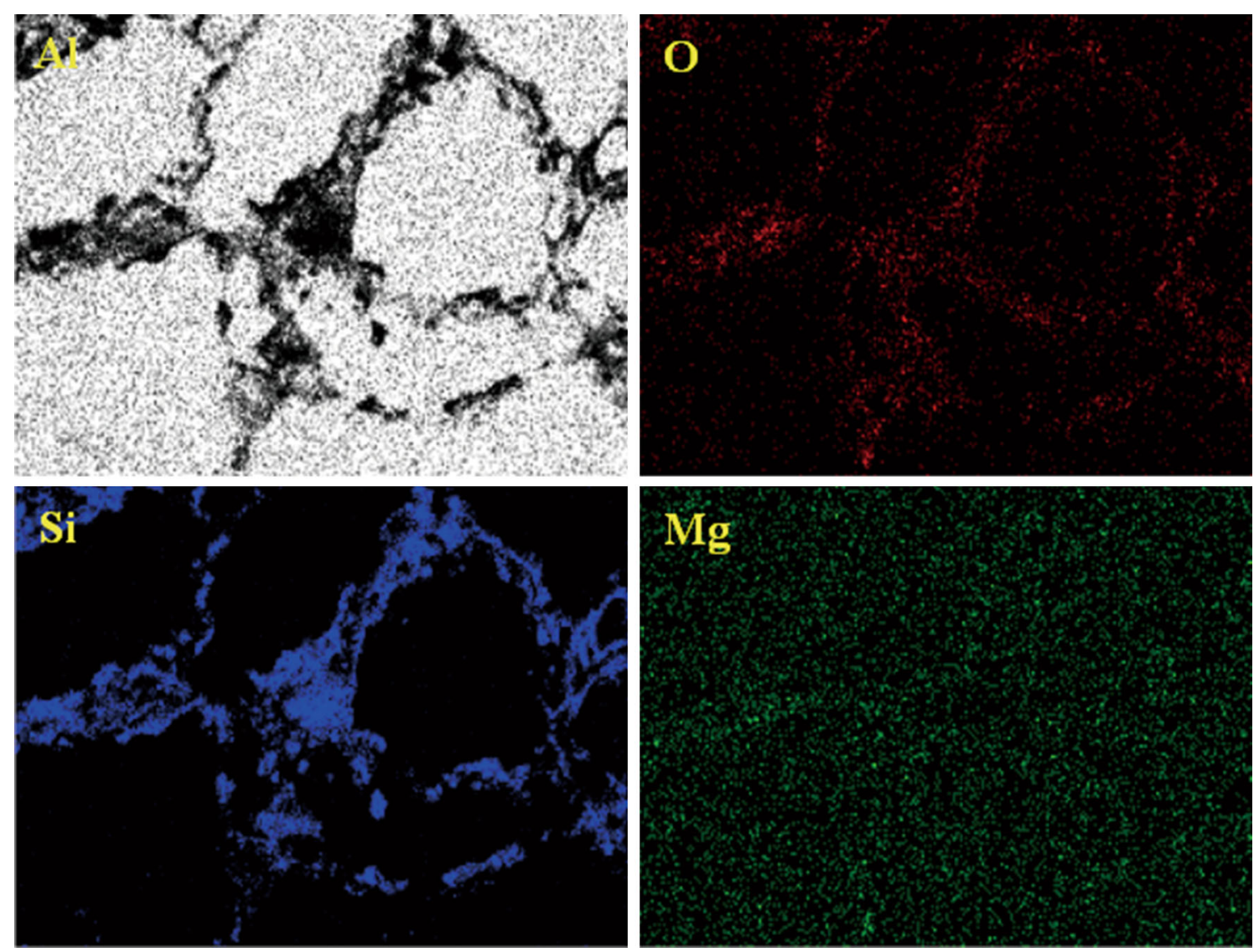

Fig. 8 Element distributions of $\mathrm{Al}, \mathrm{Mg}, \mathrm{O}, \mathrm{Si}$ in Fig. 6
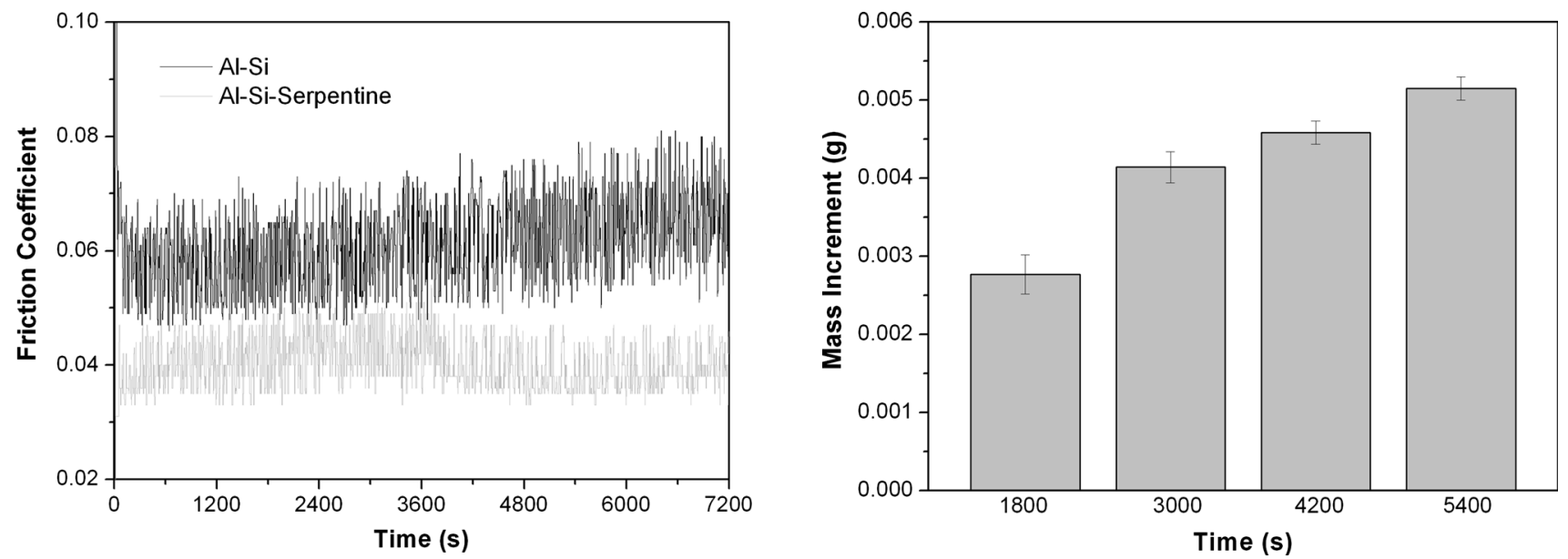

Fig. 9 Friction coefficient as a function of test time

\section{Discussion}

Previous studies [5-11] have reported that a self-repairing surface layer can be formed on worn ferrous surface. Since there are large amounts of serpentine in the oil, when the absorbed serpentine on the contact surface is consumed, the serpentine doped in the oil will be transferred to the contact

Fig. 10 Mass increment as a function of test time

surface immediately. As a result, the surface layer will be formed when the moment it is destroyed, showing the selfrepairing effect. However, in this work, the new serpentine powder will not appear until the surface of the composite is rubbed off. So, we can see a novel worn surface compared with the previous studies, as shown in Fig. 11. 

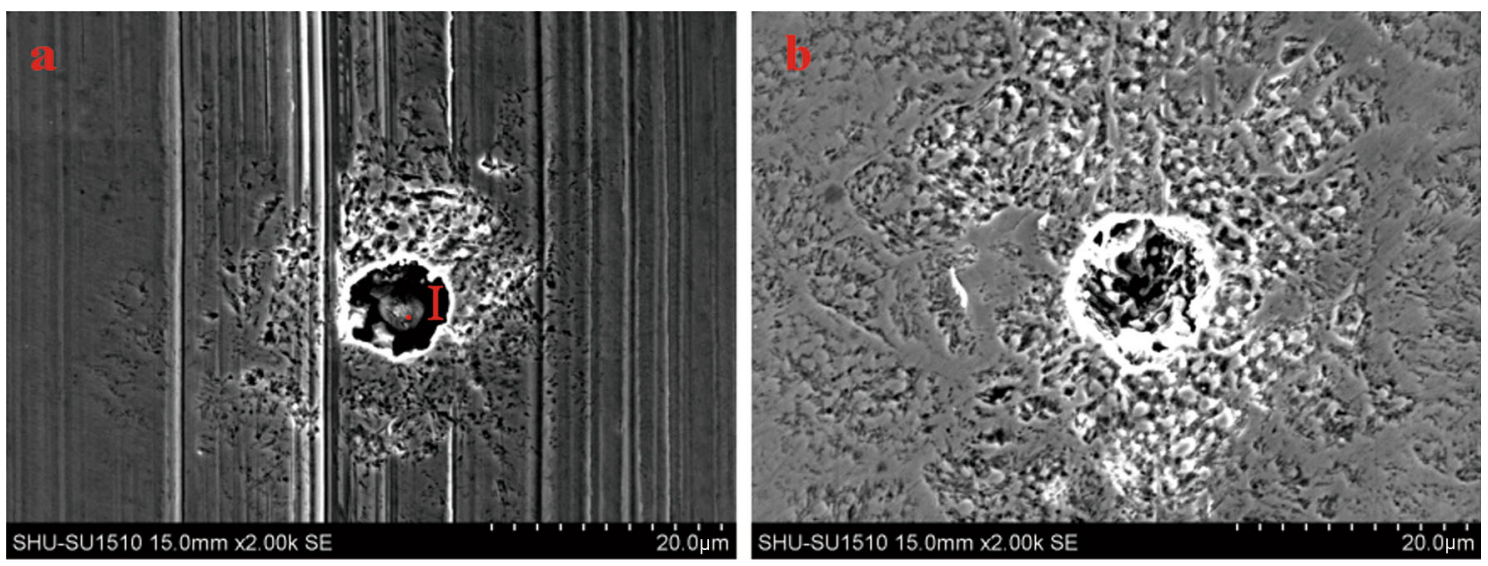

Fig. 11 Worn surface morphologies of the disk after different sliding time: a $1800 \mathrm{~s}$; b $5400 \mathrm{~s}$
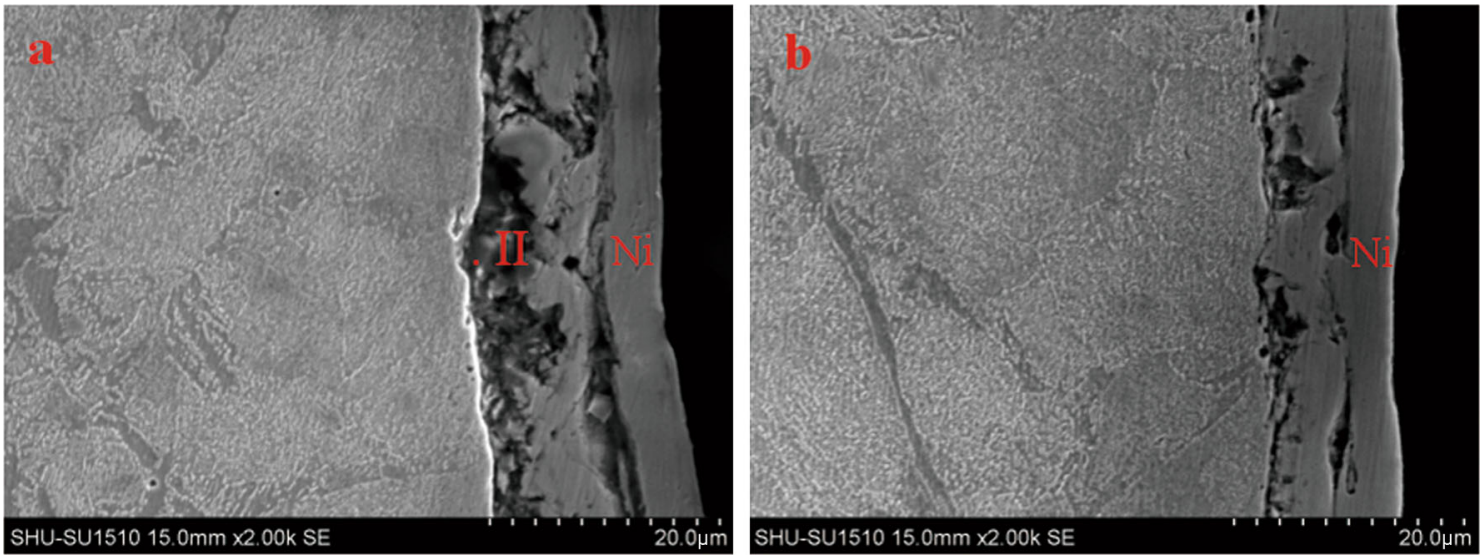

Fig. 12 Corresponding cross-sectional morphologies of a Fig. 11a, b Fig. 11b
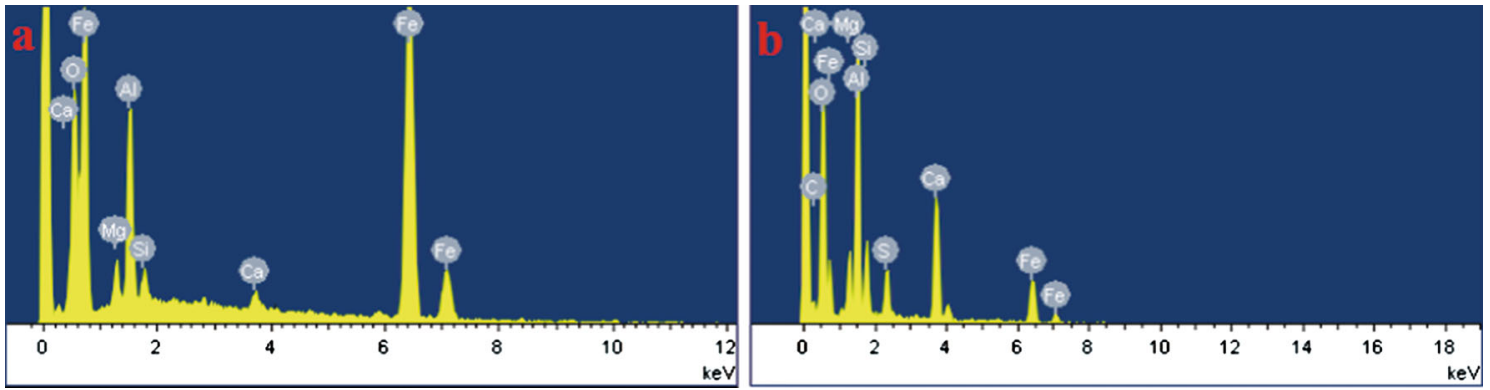

Fig. 13 EDS spectra of a point I in Fig. 11; b point II in Fig. 12

Commonly, the formation of the self-repairing protective layer can be concluded as follows: with the local pressure, friction heat, and shearing force applied [15], the serpentine particles were adhered to the contact surface [12]. In addition, crystal fracture of layered serpentine for the weak Van der Waals forces between layers and bond breakage of $\mathrm{Si}-\mathrm{O}, \mathrm{Mg}-\mathrm{O}$, and $\mathrm{Al}-\mathrm{O}$ should be mechanically initiated [11]. Finally, it is believed that oxygen atoms released by serpentine would tribochemically act with iron atoms on the worn surface to form the self- repairing surface layer [5]. Since the mechanism of the formation of the self-repairing surface layer was conjectured with serpentine doped in the lubricant [5-15], this work tries to prove the mechanism in the other view with serpentine filled in the composite.

Figure 14 is the diagrammatic model of the self-repairing surface layer. The friction brought fresh surfaces of the steel where the activity of $\mathrm{Fe}$ as catalyzer was enhanced [24]. As reported in Sect. 3, the specific surface area and the adsorptive capacity of serpentine could be improved 


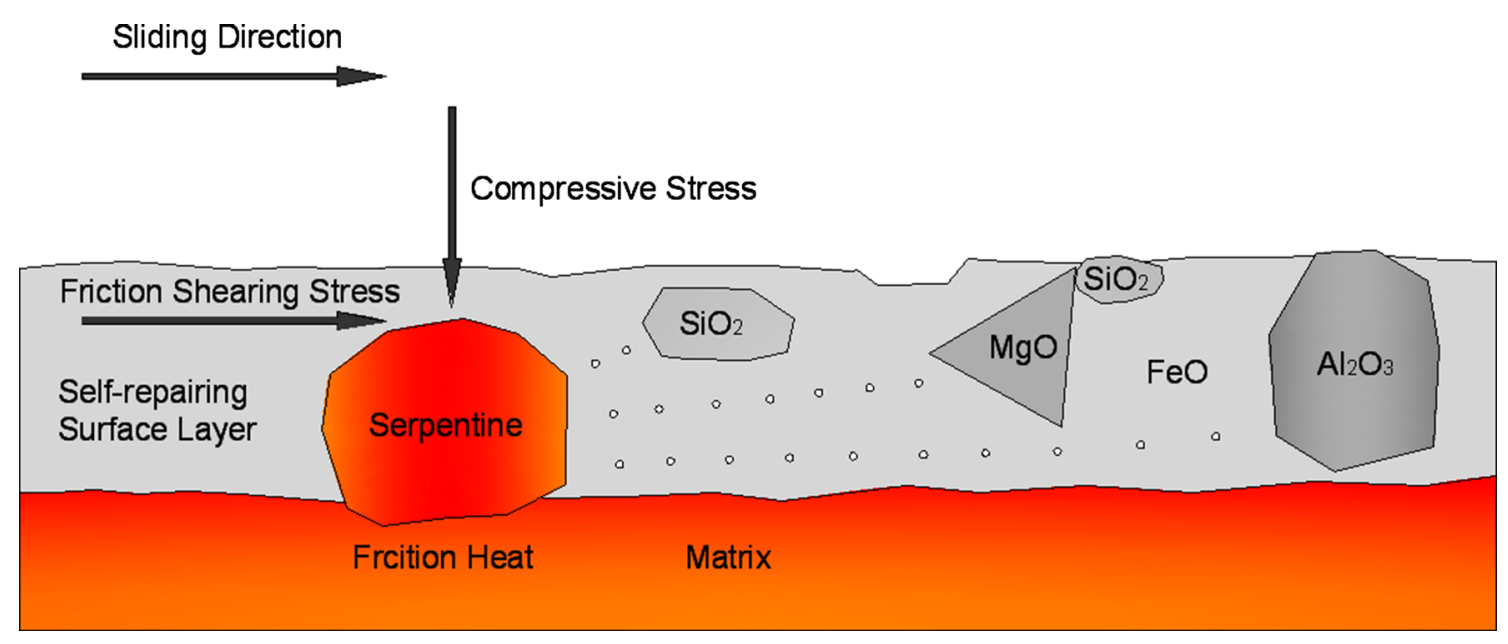

Fig. 14 Diagrammatic model of the self-repairing surface layer

after sintering at $560{ }^{\circ} \mathrm{C}$. The serpentine in the boundaries of the $\mathrm{Al}$ particles (Fig. 8) would be rubbed into the worn surface and be accumulated in the furrows and scratches of the matrix with the effect of the friction shearing stress and compressive stress. Under the effect of compressive stress, friction shearing stress, and friction heat, an oxidation reaction would be more easy to occur between the fresh friction surface and the sintered serpentine. Mechanochemical/thermochemical reaction happened between the serpentine powder and the Fe matrix contributing to the forming of iron oxide layer (Fig. 13). Elements or oxides originated from serpentine and the composite were generated as $\mathrm{SiO}_{2}, \mathrm{MgO}$, and $\mathrm{Al}_{2} \mathrm{O}_{3}$ particles (Fig. 13). The particles were embedded in the surface layer to harden it, forming the self-repairing surface layer (Fig. 12).

The surface layer was thus covered completely on the worn surface, making it smooth and no more abrasive wear morphology could be found on it (Fig. 11). On the other side, the micro-holes (Figs. 11, 12) of the coated surface layer would capture the abrasive particles to prevent abrasion, reducing the friction coefficient. In addition, it has been reported that the friction process would dehydrate absorbed water from the serpentine powder [25], and hydrous phases are less dense than anhydrous phases [24]. Furthermore, the elastic constants of serpentine increase monotonically with compression increase [26]. Therefore, with the sliding time prolonged, the surface layer would get higher elastic constants and became more compact, dense, and uniform. Thus, the friction coefficient of the composite containing serpentine was lower than that of the traditional Al-Si composite (Fig. 9).

\section{Conclusions}

Serpentine powders were sintered to make the serpentinereinforced Al-matrix composites. A surface layer was coated on the worn surface when the composites were slid against steel. Through observing the sintered serpentine powders and the tribological behavior of the surface layer, the following conclusions can be drawn:

1. After sintering, dehydration and dehydroxylation reactions happened, which endowed serpentine powders with better capability of oxygen release and adsorptive capacity. Serpentine powders were distributed mainly in the boundaries of the $\mathrm{Al}$ particles.

2. Under the effect of compressive stress and friction shearing stress, the activated serpentine powder was deeply absorbed on the worn surface and embedded in the furrows and scratches of the matrix, forming a selfrepairing surface layer to reduce friction coefficient.

3. The surface layer coated by serpentine was compact, dense, and uniform after continued friction, compensating the worn loss and increasing the matrix mass.

Acknowledgements This work was supported by the National Natural Science Foundation of China (Grant Nos. 50975166 and 51475280) and the Excellent Engineer Training Program (Metallic material engineering of Shanghai University) of Ministry of Education, China.

\section{References}

[1] B.S. Zhang, B.S. Xu, Y. Xu, Z.X. Ba, Z.Z. Wang, Appl. Surf. Sci. 285, 759 (2013) 
[2] Y.W. Zhang, Z.P. Li, J.C. Yan, T.H. Ren, Y.D. Zhao, Ind. Lubr. Tribol. 68, 1 (2016)

[3] B. Reynard, Lithos 178, 171 (2013)

[4] J.W. Wu, X. Wang, L.H. Zhou, X.C. Wei, W.R. Wang, Tribol. Lett. 65, 93 (2017)

[5] Y.S. Jin, S.H. Li, Z.Y. Zhang, H. Yang, F. Wang, Tribol. Int. 37, 561 (2004)

[6] C.F. Higgs III, E.Y.A. Wornyoh, Wear 264, 131 (2008)

[7] F.Y. Zhao, M. Kasrai, T.K. Sham, Z.M. Bai, Tribol. Lett. 50, 287 (2013)

[8] L.I. Pogodaev, I.A. Buynaovskii, E.Y. Kryukov, J. Mach. Manuf. Reliab. 38, 476 (2009)

[9] H.L. Yu, Y. Xu, P.J. Shi, H.M. Wang, M. Wei, K.K. Zhao, B.S. $\mathrm{Xu}$, Wear 297, 802 (2013)

[10] F. Wang, Mater. Sci. Eng., A 399, 271 (2005)

[11] H.L. Yu, Y. Xu, P.J. Shi, Tribol. Int. 43, 667 (2010)

[12] B.S. Zhang, Y. Xu, F. Gao, P.J. Shi, B.S. Xu, Y.X. Wu, Appl. Surf. Sci. 257, 2540 (2011)

[13] Z.N. Jia, Y.L. Yang, J.J. Chen, X.J. Yu, Wear 268, 996 (2010)

[14] Y.L. Yang, J. Ma, X.W. Qi, X.S. Meng, Wear 318, 202 (2014)

[15] H.L. Yu, Y. Xu, P.J. Shi, H.M. Wang, W. Zhang, B.S. Xu, Tribol. Int. 44, 1736 (2011)
[16] X. Wang, J.W. Wu, X.C. Wei, R.D. Liu, Q. Cao, Ind. Lubr. Tribol. 69, 158 (2017)

[17] R.X. Zheng, H. Yang, T. Liu, K. Ameyama, C.L. Ma, Mater. Des. 53, 512 (2014)

[18] Z. Sadeghian, S. Zohari, B. Lotfi, C. Broeckman, J. Alloys Compd. 589, 157 (2014)

[19] V. Umasankar, M.A. Xavior, S. Karthikeyan, J. Alloys Compd. 582, 380 (2014)

[20] H.Z. Lai, S.Q. Wang, N. Yu, Acta Miner. Sin. 23, 124 (2003)

[21] X.W. Qi, L. Lu, Z.N. Jia, Y.L. Yang, H.R. Liu, Tribol. Int. 49, 53 (2012)

[22] M. Megahed, M.A. Attia, M. Abdelhameed, A.G. El-Shafei, Acta Metall. Sin. (Engl. Lett.) 30, 781 (2017)

[23] H. Ashrafi, M.H. Enayati, R. Emadi, Acta Metall. Sin. (Engl. Lett.) 28, 83 (2015)

[24] Y. Yang, J.L. Gu, F.Y. Kang, X.Q. Kong, W. Mo, Appl. Surf. Sci. 253, 7549 (2007)

[25] X.W. Qi, Z.N. Jia, Y.L. Yang, B.L. Fan, Tribol. Int. 44, 805 (2011)

[26] M. Mookherjee, L. Stixrude, Earth Planet Sci. Lett. 279, 11 (2009) 